\title{
Beilschmiedia rigida (Mez) Kosterm. (Lauraceae): diferenciação e desenvolvimento da lâmina foliar
}

\author{
Carlos Alexandre Marques ${ }^{1,2}$ \\ Cláudia Franca Barros ${ }^{3}$ \\ Cecília Gonçalves Costa ${ }^{3,4}$
}

\begin{abstract}
RESUMO
Neste trabalho descreve-se o desenvolvimento da lâmina foliar de Beilschmiedia rigida (Mez) Kosterm., desde o surgimento do primórdio foliar no ápice vegetativo até sua completa expansão. São apontadas características como - presença de tricomas apenas nas folhas jovens; ocorrência de projeções parietais e invaginações protoplasmáticas nas paredes anticlinais e periclinais das células epidérmicas; estômatos paracíticos de origem mesoperígena; hipoderme em três estratos na face adaxial e em apenas um na face abaxial da lâmina foliar e células secretoras que surgem nos primeiros estágios de diferenciação da folha assim como idioblastos cristalíferos em grupos.
\end{abstract}

Palavras-chaves: Lauraceae, Beilschmiedia rigida, morfogênese, anatomia foliar, Floresta Atlântica.

\begin{abstract}
The differentiation and development of leaves of Beilschmiedia rigida from the leaf primordium to the complete leaf expansion are described. Characteristics as - presence of trichomes in young leafs only, occurrence of walls and protoplasmic projections in the anticlinal and periclinal walls of epidermal cells, paracitic stomata of mesoperiginous origin; three layers of hipodermis in the adaxial face and one layer in the abaxial face of leaf blade and secretory cells and cristaliferous idioblasts groups that arises in the leaf primordium were pointed.
\end{abstract}

Key words: Lauraceae, Beilschmiedia rigida, morphogenesis, leaf anatomy, Atlantic Rain Forest.

\section{INTRODUÇÃO}

A família Lauraceae é representada por 49 gêneros com 2.500-3.000 espécies típicas das florestas tropicais e subtropicais (Werff \& Richter, 1996). Alguns de seus gêneros têm ocorrência muito restrita como Ravensara, encontrado apenas em Madagascar. Outros, a exemplo de Ocotea são distribuídos nas Américas do Sul e Central e outros ainda, como Beilshmiedia e Cryptocarya encontram-se amplamente dispersos nos trópicos (Metcalfe, 1987).
As espécies de Lauraceae apresentam características morfológicas marcantes: porte geralmente arbóreo ou arbustivo, raramente lianescente; folhas alternas, inteiras, peninérveas ou 3-5 nérveas, glabras ou pilosas; inflorescências paniculadas e fruto do tipo baga, drupa ou núcula (Barroso et al., 1999; 2002). A família destaca-se pelo grande número de espécies economicamente importantes, entre as quais podem ser mencionadas Aniba duckei Ducke e Sassafras albidum (Nutt.) Nees, por seu uso em perfumaria e na indústria

\footnotetext{
${ }^{1}$ Trabalho de iniciação científica do primeiro autor (CNPq)

${ }^{2}$ Doutorando em Biotecnologia Vegetal e Lab. de Morfologia Vegetal, Sala A1-108, Bloco A, Depto. de Botânica, CCS, Universidade Federal do Rio de Janeiro

${ }^{3}$ Instituto de Pesquisas Jardim Botânico do Rio de Janeiro. Rua Pacheco Leão, 915, Jardim Botânico, Rio de Janeiro,

RJ, Brasil. CEP: 22460-030. e-mail: ccosta@jbrj.gov.br

${ }^{4}$ Bolsista CNPq
} 
farmacêutica; Ocotea aciphylla (Nees) Mez; Ocotea spectabilis (Meissn.) Mez e Ocotea teleiandra (Meissn.) Mez, utilizadas na medicina popular; Laurus nobilis L (louro), usado em culinária e Persea americana Mill (abacate), espécie muito conhecida por seus frutos comestíveis (Rizzini \& Mors, 1976). Outras espécies, como Beilschmiedia rigida (Mez) Kosterm, Nectandra rigida (H.B.K) Nees e Ocotea porosa (Nees.) L. Barroso fornecem madeira de lei e são amplamente usadas em marcenaria, na construção civil e na fabricação de papel (Vattimo, 1956; Barros et al., 1997b).

No Brasil, as espécies de Lauraceae ocorrem nos mais diversos ecossistemas e são uma das famílias mais representativas da Mata Atlântica no estado do Rio de Janeiro. Segundo Lima \& Guedes-Bruni (1997), somente nas áreas de floresta montana do estado ocorrem 44 espécies de Lauraceae.

Beilschmiedia rigida é endêmica da Reserva Ecológica de Macaé de Cima, localizada no município de Nova Friburgo, RJ e integra a lista de espécies que possuem maior índice de valor de importância na região (Lima \& Guedes-Bruni, 1997). Estudos prévios sobre a espécie forneceram dados relativos à florística (Guedes-Bruni et al., 1997), ao sistema reprodutivo (Gomes-da-Silva et al., 1997), à anatomia ecológica e micromorfologia foliar (Barros et al., 1997a) e à anatomia do lenho (Barros et al., 1997b).

No presente estudo acompanha-se o desenvolvimento da lâmina foliar de B. rigida, com o objetivo de esclarecer diferentes aspectos relativos à diferenciação e ao desenvolvimento de estruturas típicas da família Lauraceae, a fim de adicionar novas informações às pesquisas já desenvolvidas para a espécie.

\section{MATERIAL E MÉTODOS}

O material utilizado é procedente da Reserva Ecológica de Macaé de Cima, Nova Friburgo, RJ $\left(22^{\circ} 21^{\prime}\right.$ e $22^{\circ} 28^{\prime} \mathrm{S} ; 42^{\circ} 27^{\prime}$ e $42^{\circ}$ $35^{\prime} \mathrm{W}$ ), que apresenta temperatura média de $17,8^{\circ} \mathrm{C}$, sendo os meses de Janeiro e Fevereiro os mais quentes e Julho o mais frio. A umidade relativa é alta e a precipitação anual varia de 1.500 a 2.000 mm, sendo Dezembro o mês mais chuvoso (Guedes-Bruni et al. 1997). O espécime estudado está registrado no herbário do Instituto de Pesquisas Jardim Botânico do Rio de Janeiro (RB 292.198). Foram coletados os ápices vegetativos e folhas em diferentes estágios de desenvolvimento do primeiro ao quarto nós. Em medições previamente realizadas constatou-se que o primórdio foliar, no primeiro estágio do desenvolvimento, apresentou comprimento médio de $0,1 \mathrm{~cm}$. Já a folha completamente expandida, apresentou comprimento médio de $15 \mathrm{~cm}$.

O material coletado foi fixado em FAA em etanol 50\% (Johansen, 1940), desidratado em série etílica e emblocado em parafina (Jensen, 1962) ou historesina (Bennet et al., 1973). As secções, obtidas nos planos transversal e longitudinal, foram executadas ao micrótomo rotativo Shandon nas espessuras de 8-10 $\mu \mathrm{m}$ e de $10-12 \mu \mathrm{m}$, respectivamente, para o material emblocado em historesina e em parafina. Para observação das epidermes, utilizaram-se fragmentos da lâmina foliar diafanizada de acordo com Stritmatter (1973) ou dissociada segundo método de Jeffrey (Johansen, 1940). O material emblocado em parafina foi corado pelo processso de dupla coloração Azul de Astra-Fucsina Básica (Roeser, 1972). Quanto ao material emblocado em historesina, não se obteve êxito pelos métodos convencionais de coloração, tendose conseguido melhores resultados introduzindo algumas modificações na técnica de Bukatsch (1972). Inicialmente as seções foram deixadas em Azul de Astra 1\% por três dias. Após rápida lavagem em água destilada, foram submetidas à coloração Azul de AstraSafranina aquosa (na proporção de $95 \mathrm{ml} \mathrm{e} 5 \mathrm{ml}$, respectivamente) por 15 minutos. Usou-se permount como meio de montagem para as lâminas permanentes e glicerina 50\% para as montagens provisórias. Os testes histoquímicos, realizados em material recém- 
coletado, foram feitos para detectar a presença de alguns componentes, a saber: cutina e suberina pelo Sudan IV (Johansen, 1940); mucilagem pelo vermelho de rutênio (Jensen, 1962); oxalato de cálcio pela insolubilidade dos cristais no ácido acético e solubilidade no ácido clorídrico e no ácido sulfúrico diluído (Johansen, loc. cit) e substâncias fenólicas pelo teste de Hoepfner-Vorsatz (Reeve, 1951). Os padrões estomáticos foram definidos segundo Wilkinson (1979) e na classificação do padrão de nervação foliar, seguiram-se os conceitos de Hickey (1979).

O material foi documentado por fotomicrografias obtidas ao microscópio fotônico Olympus BH-2 em diferentes aumentos.

\section{RESULTADOS}

Os primórdios foliares originam-se em sentido acrópeto no ápice caulinar e conseqüentemente, os primórdios mais jovens encontram-se protegidos pelos que se encontram em fase mais avançada de diferenciação (Fig. 1). Secções longitudinais evidenciam que os primórdios foliares assemelham-se a protuberâncias laterais do ápice caulinar (Fig. 2).

Ainda em secção longitudinal é possível constatar, no ápice vegetativo de Beilschmiedia rigida, a ocorrência da túnica em dois estratos e do corpo, em cinco (Fig. 2). As células do primeiro estrato da túnica, por divisões anticlinais, dão origem à protoderme, enquanto a segunda camada determina o surgimento dos estratos subprotodérmicos que vão originar a hipoderme. Concomitantemente, divisões anticlinais, periclinais e oblíquas das células do corpo vão contribuir para a expansão do eixo e para adicionar novas células ao meristema fundamental. Nesta fase inicial de diferenciação, já se observam os elementos precursores das células secretoras de mucilagem (Fig. 3).

Secções transversais em um primórdio com aproximadamente $0,1 \mathrm{~cm}$ de extensão revelam que as células da primeira camada subprotodérmica, na face adaxial, dividem-se no sentido periclinal, originando a hipoderme em dois estratos (Fig. 4). Ocasionalmente, algumas células do segundo estrato hipodérmico se dividem para constituir os três estratos hipodérmicos, observados em alguns trechos da lâmina foliar na face adaxial. A camada subprotodérmica na face abaxial não se divide, e conseqüentemente, nessa face, a hipoderme apresenta-se em um só estrato.

A primeira camada de células subjacentes à hipoderme adaxial se diferencia e dá origem ao primeiro estrato de parênquima paliçádico (Fig. 5) que, posteriormente, também se divide, para formar os dois estratos paliçádicos. A seguir, os elementos celulares da face abaxial diferenciam-se e sofrem divisões predominantemente no plano anticlinal para constituir o parênquima lacunoso que, nas folhas completamente expandidas, apresentase em 7-9 estratos. As células da primeira e da segunda camada adjacentes à hipoderme abaxial apresentam-se alongadas no sentido anticlinal, ocorrendo espaços intercelulares entre as mesmas (Fig. 6).

Nos primeiros estágios de desenvolvimento do primórdio foliar, ocorrem células que se destacam por suas dimensões, pelo citoplasma denso com vacúolos pequenos e pelo núcleo conspícuo (Fig. 3). São os precursores das células secretoras. Progressivamente, os vacúolos se fusionam em um vacúolo único. Esta fase é atingida muito cedo, quando as demais células do mesofilo ainda se encontram pouco diferenciadas (Fig. 7). As células secretoras, depois de completamente diferenciadas, apresentam paredes relativamente espessas com forte afinidade pelo Sudan IV, o que indica a presença de suberina. Tais células são frequientes no mesofilo (Fig. 6), junto à nervura mediana, no bordo foliar e no pecíolo. Raramente ocorrem células secretoras geminadas. Pela reação positiva ao vermelho de rutênio e ao azul de Astra, foi comprovada a natureza mucilaginosa de seu conteúdo. 


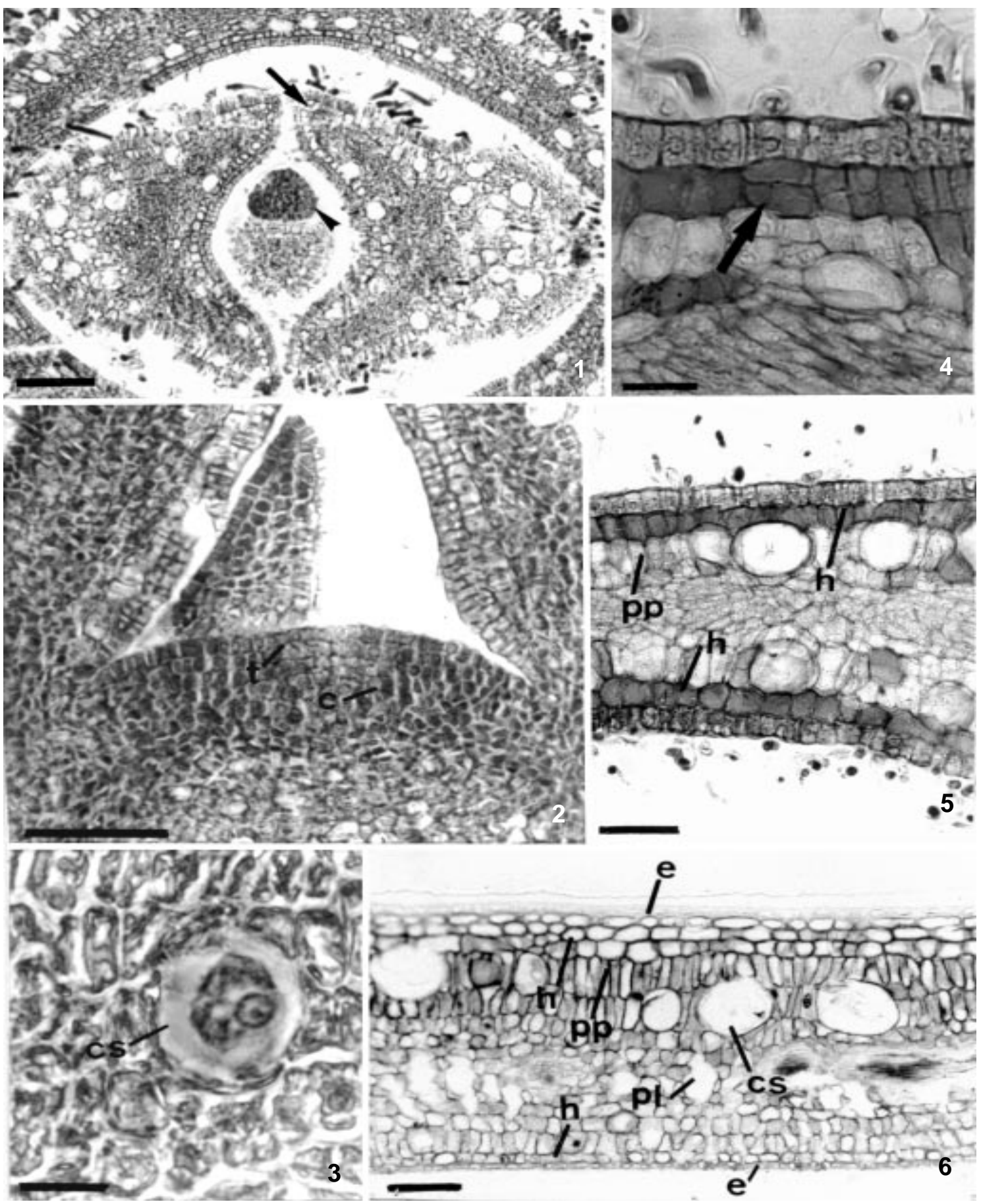

Figura 1: Ápice vegetativo de Beilschmiedia rigida (ST), evidenciando um primórdio jovem ( $\triangleright$ ), protegido por outros em estágio mais avançado de desenvolvimento $(\rightarrow)$. Barra $=150 \mu \mathrm{m}$. Figura 2 - Ápice vegetativo de Beilschmiedia rigida $(\mathrm{SL})$, em que se observa a túnica (t), o corpo (c) e primórdios foliares. Barra $=20 \mu \mathrm{m}$. Figura 3 - Estágio inicial da formação da célula secretora de mucilagem (cs). Barra $=50 \mu \mathrm{m}$. Figura $4-$ Face adaxial do primórdio foliar (ST) em que se notam as primeiras divisões periclinais da camada subprotodérmica para originar a hipoderme $(\rightarrow)$. Barra $=20 \mu \mathrm{m}$. Figura $5-$ Lâmina foliar jovem (ST), em que são observados os primeiros estratos de hipoderme nas faces adaxial e abaxial (h) e a primeira camada de parênquima paliçádico $(\mathrm{pp})$. Barra $=150 \mu \mathrm{m}$. Figura 6 - Lâmina foliar na região intercostal, ao nível do terço médio, já inteiramente diferenciada: epiderme (e), hipoderme (h), parênquima paliçádico (pp), lacunoso (pl) e células secretoras de mucilagem (cs). Barra $=150 \mu \mathrm{m}$. Abreviaturas: ST - Secção transversal; SL - Secção longitudinal. 



Figura 7: Célula secretora de mucilagem completamente diferenciada, após a fusão dos vacúolos (cs). Barra $=50 \mu \mathrm{m}$. Figura 8: Detalhe de um primórdio foliar, evidenciando cristais prismáticos (c) e um grupo de esclereídes já perfeitamente diferenciados (es). Barra $=25 \mu \mathrm{m}$. Figura 9 - Protoderme na face abaxial, evidenciando duas células-filhas (cf) precursoras do estômato e outros já completamente diferenciados. Contraste de Fase. Barra $=50 \mu \mathrm{m}$. Figura 10 - Estômato recém diferenciado apontado pela seta. Contraste de Fase. Barra $=10 \mu \mathrm{m}$. Figura 11 - Detalhe de um primórdio foliar (SL), em que se observa um tricoma bicelular $(\rightarrow)$ e outros unicelulares. Barra $=20 \mu \mathrm{m}$. Figura $12-$ Epiderme adaxial da lâmina foliar jovem, evidenciando contrafortes nas paredes anticlinais das células epidérmicas $(\rightarrow)$. Barra $=10 \mu \mathrm{m}$ 
Idioblastos portadores de cristais prismáticos surgem também precocemente e já são observados no primórdio foliar. Podem ocorrer um ou dois cristais em uma única célula meristemática. As paredes das células portadoras dos cristais tornam-se gradativamente espessas e lignificadas, dando origem a esclereídes que se encontram perfeitamente diferenciados, numa etapa em que as células adjacentes ainda estão numa fase pouco avançada de desenvolvimento. Esses idioblastos podem ser observados, tanto na lâmina foliar como no pecíolo, e freqüentemente ocorrem em grupos (Fig. 8).

Enquanto sucedem essas mudanças nos estratos internos da lâmina foliar, o sistema de revestimento também se diferencia e expande. Inicialmente, ocorre a diferenciação dos estômatos e dos tricomas. Na protoderme abaxial de um primórdio com aproximadamente 0,6 - 0,8 cm de extensão, são observados estômatos em diferentes fases de desenvolvimento. Foi possível verificar inicialmente, a divisão desigual de uma célula protodérmica, para dar origem a duas célulasfilhas (Fig. 9). A seguir, uma delas se diferencia como célula-mãe do estômato, originando as duas células-guarda. A célula resultante da divisão inicial da célula protodérmica e aquela que teve origem na segunda divisão vão constituir as duas células subsidiárias (Fig. 10).

Com certa freqüência podem ocorrer estômatos anômalos e mais raramente, estômatos geminados e contíguos.

Os tricomas são observados em grande número, em ambas as epidermes, nas primeiras fases de desenvolvimento do primórdio foliar (Fig. 11). Sua diferenciação também não é sincronizada, observando-se em um mesmo primórdio, tricomas em diferentes estágios de desenvolvimento. No processo de formação dos tricomas, uma célula protodérmica se expande, seu núcleo migra para a região apical e as paredes celulares se espessam. Depois de completamente desenvolvido, o tricoma apresenta-se levemente fletido em direção à lâmina foliar. Há predominância de tricomas unicelulares, embora com menos freqüência, ocorram tricomas bicelulares (Fig. 11). À medida que o primórdio foliar se expande, observa-se um processo gradual de senescência dos tricomas. Estes, ao cair, não deixam cicatriz e não são observados nas folhas completamente expandidas.

Enquanto ocorre a diferenciação dos tricomas e dos estômatos, as paredes anticlinais das demais células protodérmicas apresentamse delgadas com traçado reto ou levemente curvo. À proporção que a diferenciação de tais células progride, suas paredes, de modo particular as periclinais externas e as anticlinais, se espessam de maneira desigual, o que propicia o surgimento de projeções parietais e invaginações protoplasmáticas nessas paredes (Fig. 12). Esses aspectos são observados em folhas completamente expandidas, tanto em vista frontal como em secções transversais da lâmina foliar (Fig. 13).

A diferenciação do bordo acompanha a das demais regiões da lâmina foliar. Na figura 14 observa-se $\mathrm{o}$ aspecto do bordo em uma folha com cerca de $4 \mathrm{~cm}$ de extensão.

Em primórdios foliares recém-formados, o procâmbio apresenta-se como uma faixa contínua na porção central da lâmina jovem. As células procambiais têm o aspecto alongado típico e núcleo conspícuo. No curso do desenvolvimento, o floema surge em fase anterior ao xilema. Células do parênquima floemático, situadas externamente em relação aos elementos condutores, diferenciam-se como fibras perivasculares. Na lâmina foliar jovem (Fig. 17), o sistema vascular apresentase como dois arcos justapostos, interrompidos nas extremidades pelas fibras perivasculares, após completa diferenciação.

Braquiesclereídes e células secretoras ocorrem nas proximidades do sistema vascular (Fig. 18).

As nervuras de menor calibre surgem após a diferenciação da nervura mediana. As nervuras de segunda ordem seguem até as imediações da margem foliar e se anastomosam, formando arcos proeminentes, 

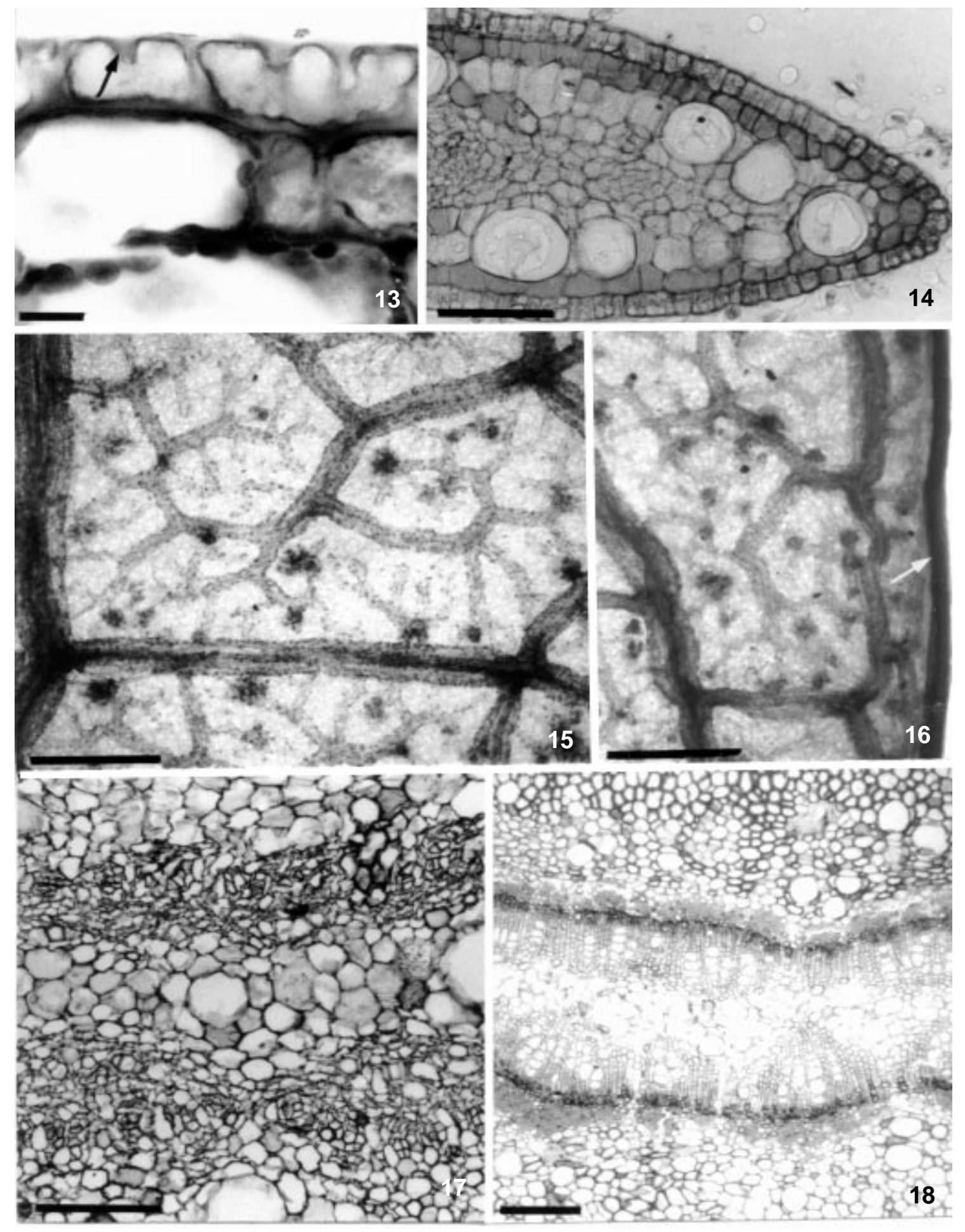

Figura 13: Lâmina foliar (ST) evidenciando contrafortes $(\rightarrow)$ na parede periclinal externa da célula epidérmica. Barra $=$ $10 \mu \mathrm{m}$. Figura 14: Bordo foliar em estágio avançado de diferenciação. Barra $=50 \mu \mathrm{m}$. Figura 15: Detalhe das aréolas na lâmina foliar. Barra $=250 \mu \mathrm{m}$. Figura 16: Venação marginal em detalhe $(\rightarrow)$. Barra $=250 \mu \mathrm{m}$. Figura 17: Detalhe do sistema vascular ao nível da nervura mediana da folha jovem. Barra $=50 \mu \mathrm{m}$. Figura 18: Detalhe do sistema vascular ao nível da nervura mediana da folha completamente expandida, na região do terço médio. Barra $=100 \mu \mathrm{m}$.

Abreviaturas: ST - Secção transversal. 
caracterizando o padrão de venação camptódromo-broquidódromo. Pequenas ramificações partem dos arcos em direção à margem e vão constituir a nervura fimbrial (Fig. 15). A rede de venação vista em detalhe apresenta aréolas ortogonais, com terminações vasculares ramificadas (Fig. 16).

\section{DISCUSSÃO}

O desenvolvimento dos primórdios foliares em Beilschmiedia rigida ocorre no sentido acrópeto e segue os padrões referidos por Cutter (1987) e Mauseth (1988). Nesta espécie foi constatada a presença da túnica em dois estratos no ápice vegetativo, o que foi também notado por Kasapligil (1951) em duas espécies de Lauraceae, Laurus nobilis L. e Sassafras officinale Nees \& Eberm. Embora Esau (1977) assinale que a delimitação entre túnica e corpo no ápice vegetativo nem sempre é bem demarcada, no material em estudo foi possível detectar a ocorrência do corpo em cinco estratos.

A protoderme de $B$. rigida tem origem na primeira camada da túnica, que se divide no plano anticlinal, o que vem corroborar as observações de Esau (1950) e de Olson et al. (1969) quanto à origem da protoderme. Em estágio posterior, a protoderme dá origem à epiderme. Os estratos hipodérmicos (tanto na face adaxial como na abaxial) são originados na segunda camada da túnica, diferentemente do que menciona Esau (1950), que indica o meristema fundamental como o local de origem da hipoderme. Segundo Metcalfe \& Chalk (1950), Beilschmiedia figura entre os gêneros de Lauraceae com hipoderme simples. Em B. rigida foi constatada hipoderme uniestratificada apenas na face abaxial, enquanto na face adaxial ela é constituída por dois e até três estratos celulares.

Projeções parietais e invaginações protoplasmáticas, na face interna das paredes periclinais externas e nas paredes anticlinais das células epidérmicas conferem aspecto peculiar a essas paredes. Neste estudo, tais aspectos não foram observados em primórdios foliares de $B$. rigida e sua ocorrência confirma os estudos ultra-estruturais de Barros \& Miguens (1998), em folhas completamente expandidas. Segundo Faggetter (1987), essas flanges, moderadamente profundas ou em forma de "U", constituem um reforço ou contraforte, surgindo em diferentes ângulos da superfície periclinal. Todavia, ainda não foram realizados estudos visando avaliar essa função de reforço mecânico. Aspecto semelhante foi descrito em outras espécies de Lauraceae por Christophel et al. (1996), em Beilshmiedia obtusifolia. Barros et al. (1997a), ao estudarem a anatomia ecológica de espécies da Mata Atlântica, consideraram a diferença de espessura na parede periclinal externa de Beilschmiedia rigida um caráter geneticamente controlado, não expressando uma adaptação ao ambiente. Características aparentemente iguais têm sido observadas em espécies de outras famílias, a exemplo das Myrtaceae (Fontenelle et al., 1994), o que leva a crer que as mesmas possam desempenhar alguma função fisiológica, o que aponta a necessidade de outros estudos, a fim de que o assunto seja melhor esclarecido.

West (1969) mencionou a ocorrência de células secretoras de mucilagem em espécies de Lauraceae e Metcalfe (1987) assinalou que tais estruturas são muito comuns à família. Maron \& Fahn (1979) analisaram as células oleíferas de Laurus nobilis e Bakker et al. (1992) estudaram estruturas similares em espécies de Cinnamomum. Esses autores constataram que as células secretoras são revestidas por paredes suberizadas e se localizam geralmente no parênquima paliçádico ou no lacunoso. As paredes das células secretoras de Beilshmiedia rigida também são suberizadas e encontram-se distribuídas no parênquima paliçádico, no lacunoso e ao nível da nervura mediana e no pecíolo.

$\mathrm{O}$ mesofilo de $B$. rigida se origina pela atividade das derivadas da inicial marginal, o que vem confirmar as referências da literatura (Avery, 1933; Esau, 1950; Costa, 1989). De acordo com Metcalfe \& Chalk (1950), o 
mesofilo das espécies de Lauraceae, com poucas exceções, a exemplo de Persea, apresenta-se mais ou menos compacto com lacunas pouco desenvolvidas, o que foi também observado por Kasapligil (1951) em Laurus nobilis e corresponde ao padrão das folhas completamente expandidas de $B$. rigida.

As características foliares do material em análise parecem indicar uma estratégia de adaptação ao estresse hídrico, visto que espécies com um volume baixo de parênquima esponjoso e, conseqüentemente, células mais compactas, podem ser menos impactadas pela desidratação (James et al., 1999). Por outro lado, acredita-se que a ocorrência de hipoderme múltipla apenas na face adaxial de B. rigida represente uma adaptação contra o excesso de luminosidade, tendo em vista que a face adaxial das folhas está exposta a maior insolação (James et al., 1999). Considerando que a espécie em estudo se desenvolve numa área cujo clima é considerado superúmido (Guedes-Bruni, 1998), acredita-se que tais características xeromórficas sejam inerentes ao seu genótipo.

$\mathrm{O}$ sistema vascular de $B$. rigida surge nos primeiros estágios da ontogênese foliar e se desenvolve no sentido acrópeto, conforme parâmetros referidos por Isebrands \& Larson (1973), também mencionados por Avery (1933) e, mais recentemente, por Nelson \& Dengler (1997). Segundo Nelson \& Dengler (1997) o tecido provascular, localizado na porção correspondente à região mediana do mesofilo, dá origem à nervura mediana, na qual se originam as nervuras menores que determinam o padrão de venação foliar nas dicotiledôneas. Quanto à diferenciação dos tecidos vasculares em $B$. rigida, o floema surge em etapa anterior à do xilema no cordão procambial, o que vem confirmar as referências de Isebrands \& Larson (1973) e Esau (1977).

A importância dos tricomas em Taxonomia tem sido enfatizada por autores como Metcalfe \& Chalk (1950), Faggetter (1987) e Christophel et al. (1996). Estes autores assinalam que os tricomas unicelulares são uma característica das Lauraceae. Em Beilshmiedia rigida a presença de tricomas unicelulares nos primódios foliares é uma constante. Foram também detectados tricomas bicelulares, embora pouco freqüentes. Marques (2001) também observou tricomas bicelulares no pecíolo de Aniba firmula (Nees \& C. Mart.) Mez e Nectandra lanceolata Nees.

As folhas de $B$. rigida são hipostomáticas com estômatos paracíticos, o que vem corroborar as observações de Christophel et al. (1996) quanto às espécies família Lauraceae e de Barros et al. (1997b) para a folha completamente expandida de B. rigida. Baruah \& Nath (1997), por sua vez, referem estômatos paracíticos e pericíticos para espécies indianas de Cinnamomum. Quanto à origem, os estômatos de $B$. rigida são mesoperígenos. Avita \& Inamdar (1981), acompanhando a ontogênese dos estômatos em 12 espécies de Lauraceae, verificaram a predominância do padrão paracítico, ocorrendo também o tipo anomocítico, em menor proporção. Quanto à origem, concluíram que nessas espécies os estômatos paracíticos têm origem mesógena e os anomocíticos são perígenos.

Cristais sob as mais diversas formas são comuns no reino vegetal e representam um caráter marcante em diversas famílias. Milanez (1932) estabelece uma correlação entre a presença desses cristais e o espessamento das paredes celulares e sugere que os cristais sejam responsáveis pela formação de esclereídes em algumas famílias de dicotiledôneas. Recentemente, Huang et al. (2000) também verificaram a ocorrência conjunta de cristais e esclereídes nas espécies aquáticas Nymphoides coreana (H. Lév.) H. Hara e Nuphar schimadai. Acredita-se que em $B$. rigida possa existir uma relação entre os cristais e o espessamento das paredes das células que os contêm, propiciando assim o surgimento dos esclereídes ainda em fase inicial do desenvolvimento. Faz-se necessário, porém, o desenvolvimento de estudos complementares, necessários para comprovar tal hipótese. 


\section{AGRADECIMENTOS}

Os autores agradecem ao $\mathrm{CNPq}$ pelas bolsas concedidas, ao pesquisador Osnir Marquete e ao técnico Paulo Rogério Ferreira Dias, pela colaboração na confecção das fotomicrografias.

\section{REFERÊNCIAS BIBLIOGRÁFICAS}

Avery, Jr. G. S. 1933. Structure and development of the tobacco leaf. American Journal of Botany 20 (9): 565-592.

Avita \& Inamdar, J. A. 1981. Stomatal complex in Lauraceae; structure and ontogeny. Acta Botanica Indica 9: 5056.

Bakker, M. E.; Gerritsen, A. F \& Schaaf, P. J. Wander., 1992. Leaf anatomy of Cinnamomum Schaffer (Lauraceae), with special reference to oil and mucilage cells. Blumea 37: 1-30.

Barros, C. F.; Callado, C. H.; Cunha, M. da; Costa, C. G.; Pugialli, H. R. L.; Marquete, O. \& Machado, R. D. 1997a. Anatomia ecológica e micromorfologia foliar de espécies de floresta montana na Reserva Ecológica de Macaé de Cima. In: Lima, H. C. \& Guedes-Bruni, R. R (Edit.) Serra de Macaé de Cima: Diversidade florística e conservação em Mata Atlântica. Rio de Janeiro, Instituto de Pesquisas Jardim Botânico do Rio de Janeiro, 275-296.

Barros, C. F.; Callado, C. H.; Costa, C. G.; Pugialli, H. R. L.; Cunha, M. da \& Marquete, O. 1997b. Madeiras da Mata Atlântica - Anatomia do lenho das espécies remanescentes florestais do estado do Rio de Janeiro. Vol. I, Rio de Janeiro, Instituto de Pesquisas Jardim Botânico do Rio de Janeiro, 86 p.

Barros, C. F. \& Miguens, F. C. 1998. Ultrastructure of the epidermal cells of Beilshmiedia rigida (Mez) Kosterm. (Lauraceae). Acta Microscopica 6 (3): 451-461.
Barroso, G. M.; Morim, M. P.; Peixoto, A. L. \& Ichaso, C. L. F. 1999. Frutos e Sementes. Morfologia aplicada à sistemática de dicotiledôneas. Viçosa, Editora UFV, 443 p.

Barroso, G. M; Peixoto, A. L. Ichaso, C. L. F; Guimarães, E. F. \& Costa, C. G. 2002. Sistemática das angiospermas do Brasil. Vol. I. $2^{\text {a }}$ edição, Viçosa, Editora UFV, $309 \mathrm{p}$.

Baruah, A. \&, Nath, S. C. 1997. Foliar epidermal caracters in twelve species of Cinnamomum Schaeffer (Lauraceae) from Northestern India. Phytomorphology 47 (2): 127-134.

Bennet, H. S.; Wyrick, A. D.; Lee, S. W. \& Mc Neil, J. H. 1973. Science and art in preparing in plastic for light microscopy, with special reference to glicol methacrylate, glass knives and simples stains. Stain Technology 51 (2): 71-96.

Bukatsch, F. 1972. Bemerkungen zur doppel far buring Astrablau-Safranin. Mikrokosmos 61 (8): 255.

Christophel, D. C.; Kerrigan, R. \& Rowett, A. I. 1996. The use of cuticular features in the taxonomy of the Lauraceae. Annals of the Missouri Botanical Garden 83: 419-432.

Costa, C. G. 1989. Morfologia e anatomia dos órgãos vegetativos em desenvolvimento de Marcgravia polyantha Delp. (Marcgraviaceae). São Paulo, Tese de Doutorado, USP. $227 \mathrm{p}$.

Cutter, E. G. 1987. Anatomia vegetal (Parte II). Órgãos: experimentos $e$ interpretação. $1^{\text {a }}$ ed, São Paulo, Ed. Roca, Trad., 336 p.

Esau, K. 1950. Plant anatomy. New York, Ed. John Wiley \& Sons, 729 p.

Esau, K. 1977. Anatomy of seed plants. $2^{\text {nd }}$ ed., New York, Ed. Jonh Villey \& Sons, $550 \mathrm{p}$. 
Faggetter, C. D. 1987. Leaf cuticules (phytoglyphs) of selected Lauraceae. In: Metcalfe, C.R. Anatomy of the Dicotyledons. Vol. III. 2a ed. Oxford, Claredon Press, 157-160.

Fontenelle, G. B.; Costa, C. G. \& Machado, R. D. 1994. Foliar anatomy and micromorphology of eleven species of Eugenia L. (Myrtaceae). Botanical Journal of the Linnean Society 116 (2): 111-133.

Gomes-da-Silva, A.; Guedes-Bruni, R. R. \& Morim-de-Lima, M. P. 1997. Sistemas sexuais e recursos florais do componente arbustivo arbóreo em mata preservada na Reserva Ecológica de Macaé de Cima. In: Lima, H. C. \& Guedes-Bruni, R. R (Edit.). Serra de Macaé de Cima: Diversidade Florística e Conservação em Mata Atlântica. Instituto de Pesquisas Jardim Botânico do Rio de Janeiro, Rio de Janeiro, 187-211.

Guedes-Bruni, R. R. 1998. Composição, estrutura e similaridade florística de dossel em seis unidades de Mata Atlântica no Rio de Janeiro. São Paulo, Tese de Doutorado, Instituto de Biociências, USP, 231 p, il.

Guedes-Bruni, R. R.; Pessoa, S. V. A. \& Kurtz, B. C. 1997. Florística e Estrutura do componente arbustivo-arbóreo de um trecho preservado de floresta montana na Reserva Ecológica de Macaé de Cima. In: Lima, H. C. \& Guedes-Bruni, R. R (Edit.). Serra de Macaé de Cima: Diversidade Florística e Conservação em Mata Atlântica. Instituto de Pesquisas Jardim Botânico do Rio de Janeiro, Rio de Janeiro, 127-145.

Hickey, L. J. 1979. A Revised classification of the architecture of dicotyledonous leaves. In: Metcalfe, C.R. \& Chalk, L. (Edit.) Anatomy of the Dicotyledons. Vol. I. $2^{\text {nd }}$ ed. Oxford, Claredon Press, 25-39.

Huang, L. L. K.; Chen, S. H. \& Chen, S. J. 2000. Ultraestructural study on the formation of sclereida in the floating leaves of Nymphoides coreana and Nuphar schimadai. Botanical Bulletin of Academia Sinica 41: 283 - 291.

Isebrands, J. G. \& Larson, P. R. 1973. Anatomical changes during leaf ontogeny in Populus deltoides. American Journal of Botany, 60 (3): 199-208.

James, S. A.; Smith, W.K. \& Vogelmann, T. C. 1999. Ontogenetic differences in mesophyll structure and chlorophyll distribution in Eucaliptus globulus spp. globulus (Myrtaceae). American Journal of Botany 86 (2): 198-207.

Jensen, W. A. $1962 . \quad$ Botanical Histochemistry. $1^{\text {st }}$ ed. W.H. Freeman and Company, $408 \mathrm{p}$.

Johansen, D. A. 1940. Plant Microtechnique. $1^{\text {st }}$ ed. Mc Graw Hill Company, 503 p.

Kasapligil, B.1951. Morphological and ontogenetic studies of Umbellularia californica Nutt. and Laurus nobilis L.. University of California Publications of Botany 25 (3):115-240.

Lima, H. C. \& Guedes-Bruni, R. R. 1997. Diversidade de plantas vasculares na Reserva Ecológica de Macaé de Cima. In: Lima, H. C. \& Guedes-Bruni, R. R (Edit.). Serra de Macaé de Cima: Diversidade florística e conservação em Mata Atlântica. Instituto de Pesquisas Jardim Botânico do Rio de Janeiro, Rio de Janeiro p.29-39.

Maron, R. \& Fahn, A. 1979. Ultrastructure and development of oil cells in Laurus nobilis L. leaves. Botanical Journal of the Linnean Society 78: $31-40$.

Marques, C. A. 2001. Anatomia foliar aplicada à taxonomia de espécies de Lauraceae Lindl. Viçosa, MG. Dissertação de Mestrado, UFV, 75 p.

Mauseth, J. D. 1988. Plant anatomy. $1^{\text {st }}$ ed., Benjamin/Cummings Publishing Co., $560 \mathrm{p}$. 
Metcalfe, C. R. 1987. Anatomy of the Dicotyledons. Vol. III. $2^{\text {nd }}$ ed, Oxford, Claredon Press, p. 98-125.

Metcalfe, C. R \& Chalk, L. 1950. Anatomy of the Dicotyledons. Vol. I. $1^{\text {st }}$ ed, Oxford, Oxford Science Publications, $1155 \mathrm{p}$.

Milanez, F. R.1932. Ação modificadora do oxalato de cálcio sobre as estruturas celulares. Revista Florestal 3: 5-12.

Nelson, T. \& Dengler, N. 1997. Leaf vascular pattern formation. The Plant Cell 9: 1121-1135.

Olson, K. C.; Tibbits, T. W.; Struckmeyer, B. E. 1969. Leaf histogenesis in Lactuca sativa, with emphasis upon laticifer ontogeny. American Journal of Botany 56(10): 1212-1216.

Reeve, R. M. 1951. Histochemical tests for polyphenols in plant tissues. Stain Technology 26 (2): 91-96.

Rizzini, C. T. \& Mors, W. B. 1976. Botânica Econômica Brasileira, $1^{\text {a }}$ ed., São Paulo, EDUSP, 207 p.

Roeser, K. R. 1972. Die nadel der schwarzkiefer. Massenprodukt und kunstwerk der natur. Mikrokosmos 61 (2): 33-36.

Stritmatter, C. G. D. 1973. Nueva tecnica de diafanizacion. Boletin de la Sociedad Argentina de Botánica 15 (1):126-129.

Vattimo, I. 1956. O gênero Ocotea Aubl. no sul do Brasil - Espécies de Santa Catarina e do Paraná. Rodriguésia 18/ 19 (30/ 31): 265-349.

Werff, H. van der. \& Richter, H.G. 1996. Toward an improved classification of Lauraceae. Annals of the Missouri Botanical Garden 83: 419-432.

West, W. C. 1969. Ontogeny of oil cells in the woody Ranales. Bulletin of the Torrey Botanical Club 96 (3): 329-344.

Wilkinson, H. P. 1979. The Plant Surface (Mainly Leaf). Part I: Stomata. In: Metcalfe, C. R. \& Chalk, L. (Edit.) Anatomy of the Dicotyledons. Vol. I. $2^{\text {nd }}$ ed. Oxford, Claredon Press, 98-117. 